\title{
Removal of small trihalomethane precursors from aqueous solution by nanofiltration
}

\author{
Yi-Li Lin ${ }^{a}$, Pen-Chi Chiang a,*,1, E.-E. Chang ${ }^{\mathrm{b}, 2}$ \\ ${ }^{a}$ Graduate Institute of Environmental Engineering, National Taiwan University, 71 Chou-Shan Road, Taipei, Taiwan \\ ${ }^{\mathrm{b}}$ Department of Biochemistry, Taipei Medical University, 250 Wu-Hsing Street, Taipei 110, Taiwan
}

Received 16 June 2006; received in revised form 20 November 2006; accepted 21 November 2006

Available online 30 November 2006

\begin{abstract}
The removal of small trihalomethane precursors (THMPs) from aqueous solution by two commercial nanofiltration membranes (NF70 and NF270) was investigated. Resorcinol, phloroglucinol, and 3-hydroxybenzoic acid were selected as model compounds of small THMPs, while tannic acid was chosen as a medium molecular disinfection by-product (DBP) precursor for comparison. The performance of nanofiltration membranes were evaluated by introducing polyethylene glycol (PEG) solutions and uncharged saccharides to estimate molecular weight cut-off (MWCO) and membrane pore radii, respectively. The streaming potential was measured to estimate the membrane surface charge at different $\mathrm{pH}$ values, which reveals that the NF270 membrane is more $\mathrm{pH}$-sensitive than the NF70 membrane. The rejections of the above selected THMPs were assessed under various $\mathrm{pH}$ values, and the removal efficiencies of THMPs for both membranes at high $\mathrm{pH}$ values are reasonably well. Charge exclusion is the prevailing mechanism for the selected small model compounds retended by the negatively charged nanofiltration membranes, while size exclusion and adsorption are controlled mechanisms but not sufficient for the rejection of unionized small organic molecules. In general, the NF270 membrane exhibits the superior permeation rate value, which takes an advantage over the NF70 membrane from the aspect of energy conservation.
\end{abstract}

(C) 2006 Elsevier B.V. All rights reserved.

Keywords: Nanofiltration; Membrane; Trihalomethane precursor; Disinfection by-product; Drinking water production

\section{Introduction}

Trihalomethanes (THMs) are the major disinfection byproducts (DBPs) but not naturally present in ground or surface waters. Certain organic compounds such as humic acid and fulvic acid called THM precursors (THMPs) are able to form THMs when reacting with chlorine in the disinfection process. Previous studies have demonstrated that THMs cause liver, kidney or central nervous system problems [1-2]. Therefore, the maximum contaminant levels (MCL) of THMs were promulgated by many nations to protect public health [3-7]. US EPA is even adopting more stringent MCLs of THMs from 80 to $40 \mu \mathrm{g} / \mathrm{L}$ in the stage 2 disinfectants/DBP rule [8].

\footnotetext{
* Corresponding author. Tel.: +88622362 2510; fax: +886223661642. E-mail addresses: f88541104@ntu.edu.tw (Y.-L. Lin),

pcchiang@ntu.edu.tw (P.-C. Chiang), eechang@ @tmu.edu.tw (E.-E. Chang).

1 Tel.: +88622362 2510; fax: +886223661642.

2 Tel.: +88622736 9236; fax: +886227369236.
}

As chlorine is a widely used disinfectant, the reduction of THMs formation potential (THMFP) is very important. Although the THMs can be removed by introducing the advanced treatment process, it is not feasible from the economic point of view. The usage of substituting disinfectant such as chloramine has raised attention of the formation of $N$-nitrosodimethylamine (NDMA) by-product, which is an emerging water contaminant and is a probable human carcinogen classified by the US EPA [9]. On the other hand, removing THMPs before chlorination is a more effective and economic THMs control technology than the previous methods.

It is well known that the traditional coagulation process in a water treatment plant is not effective in removing small THMPs, while the membrane process has been proven to be effective [10-14]. Nanofiltration (NF), with molecular-weightcutoff (MWCO) between the range of ultrafiltration (UF) and reverse osmosis (RO), was found to be more cost effective than $\mathrm{RO}$ due to lower operating pressure and has higher rejection efficiencies for small organics and multivalent ions than UF. Therefore, in various applications, $\mathrm{RO}$ was replaced with NF 
for a higher membrane flux and significantly better permeate water quality. Many researchers have shown that NF membrane technology provides very high removal of natural organic matter (NOM) in drinking water treatment [10-14]. Owen et al. [11] proposed that NF with a relatively lower MWCO of 400-800 Da is effective in controlling the formations of DBPs. Retentions of various micropollutants by NF membranes were also reported by several researchers [12-14].

NF now is competitive with other NOM removal technologies such as conventional clarification and GAC adsorption because of the following advantages: simplicity of operation, development of higher flux membrane with low fouling potentials, and lower membrane costs [15]. Some researchers have indicated that membrane costs are comparable to or lower than conventional treatment for small systems of $<20,000 \mathrm{~m}^{3} /$ day, or $5 \mathrm{mg} /$ day (million gallons per day) [15-16]. However, there are still a lot of unknowns in the removal mechanisms by NF membranes because the rejections of solutes by NF membrane are rather complicated. Membrane properties such as hydrophobicity, membrane charge, membrane pore size, potential for fouling, resistance to temperature, retention properties and permeability dramatically affect the filtration process. Solute properties such as dipole moment and hydrophibicity also affect the separation efficiency by adsorbing or interacting with membrane surfaces [17-18].

Two main solute retention mechanisms such as size (sieving or steric interaction) and charge (Donnan) effects are generally discussed in the area of membrane science and technology. Size exclusion is the main separation mechanism for uncharged solutes based on the relationship between the membrane pore size and permeating molecule size, while charge exclusion is caused by electrostatic interactions between the charged permeating species and the charged membrane surface. However, the contributions of these two basic mechanisms in the NF process cannot be assessed simply and accurately because of the uncertainty of involving parameters. The NF separation performance is usually evaluated on a case by case basis, and many researchers describe the solute transport mechanisms with numerous kinds of models, such as the Spiegler-Kedem model [19], Teorell-Mayer-Sievers and Steric Hindrance Pore (SHP) model [20], and the hindrance model [21].

Most organic matters that are responsible for major DBP precursors in Taiwan source water are small to medium compounds, with a molecular weight near or less than $1 \mathrm{kDa}$ [22-24], which was consistent with the findings suggested by Amy et al. [25] that the majority of THMPs are present in apparent molecular weight (AMW) fractions less than $1 \mathrm{kDa}$. Evidence shows that resorcinol structures in aquatic humic materials are the major THMPs in colored waters [26], and the amount of chloroform that occurred by substituted phenols is affected by the position of chloror or hydroxyl atoms in the phenolic compound [1]. Several studies also suggest that aliphatic carboxylic acids, hydroxybenzoic acids, phenols and pyrrole derivatives are reactive substrates of organic precursors for THM formation [27-28]. Resorcinol is known to affect the hormone production of the human thyroid. The hazardous score of resorcinol is 23.9 in accordance to the Indiana Relative Chemical Hazard Score
(IRCHS) database [29], which is considered highly hazardous. Since the very limited study on small aromatic DBP precursors with different functional groups and their treatabilities by nanofiltration, the three small organic compounds (resorcinol, phloroglucinol, and 3-hydrobenzoic acid) with different functional groups and high THMFP were selected to investigate their respective performance and removal mechanisms treated by the NF membranes.

The objectives of this research were to assess the characteristics of two commercial nanofiltration membranes (NF70 and NF270) and then to determine the efficiencies of these two membranes for removing small THMPs. Tannic acid was chosen as a major medium molecular DBP precursor for comparison. The performances of these two NF membranes were examined with uncharged solutes at the beginning of the experiments. The membrane surface charge was estimated by measuring the streaming potential. The effects of solute types on filtration and the retention mechanisms at various levels of $\mathrm{pH}$ were also investigated.

\section{Materials and methods}

\subsection{Membranes and model compounds}

In this study, two types of commercial thin-film polyamide NF membranes, NF70 and NF270, produced by Dow-FilmTec were examined. Table 1 summarizes the characteristics of NF70 and NF270 membranes. Membranes of NF70 and NF270 with surface areas of $46.2 \mathrm{~cm}^{2}$ were used throughout this research.

Four model compounds with different functional groups of benzene i.e., carboxylic and phenolic groups, were used. Phloroglucinol (1,3,5-trihroxybenzene), resorcinol (1,3dihydroxybenzene) and 3-hydroxybenzoic acid were chosen as small THMPs, while tannic acid was chosen as the medium molar mass compound. All model compounds were purchased from Riedel-de Haën (Germany). Table 2 shows the properties of the model compounds and Fig. 1 shows the structure of the model compounds. All stock solutions were prepared using

Table 1

Characteristics of NF70 and NF270 membranes

\begin{tabular}{|c|c|c|}
\hline & \multicolumn{2}{|l|}{ Parameter } \\
\hline & NF70 & NF270 \\
\hline Manufacture & Dow-FilmTec & Dow-FilmTec \\
\hline MWCO (Da) & 250 & $300^{\mathrm{a}}$ \\
\hline Materials & $\begin{array}{l}0.2 \mu \mathrm{m} \text { crosslinked } \\
\text { aromatic } \\
\text { polyamide }+0.46 \mu \mathrm{m} \\
\text { polysulfone }\end{array}$ & $\begin{array}{l}\text { Semiaromatic } \\
\text { piperzine-based aromatic } \\
\text { polyamide layer on top of } \\
\text { a polysulfone microporus } \\
\text { support reinforced with a } \\
\text { polyester non-woven } \\
\text { backing layer }\end{array}$ \\
\hline $\mathrm{CaCl}_{2}$ rejection $(\%)$ & $85-95$ & $40-60$ \\
\hline $\mathrm{MgSO}_{4}$ rejection $(\%)$ & 98 & $>97$ \\
\hline Charge (neutral pH) & Negative & Negative \\
\hline
\end{tabular}

\footnotetext{
a Estimated in this study.
} 
Table 2

Physico-chemical characteristics of the model compounds used in this study

\begin{tabular}{|c|c|c|c|c|}
\hline & \multicolumn{4}{|l|}{ Model compound } \\
\hline & Resorcinol & Phloroglucinol & 3-Hydroxybenzoic acid & Tannic acid \\
\hline Molecular formula & $\mathrm{C}_{6} \mathrm{H}_{6} \mathrm{O}_{2}$ & $\mathrm{C}_{6} \mathrm{H}_{6} \mathrm{O}_{3}$ & $\mathrm{C}_{7} \mathrm{H}_{6} \mathrm{O}_{3}$ & $\mathrm{C}_{76} \mathrm{H}_{52} \mathrm{O}_{46}$ \\
\hline CAS registry number & $108-46-3$ & $108-73-6$ & $99-06-9$ & NA \\
\hline Molecular weight & 110.11 & 126.11 & 138.12 & 1701.24 \\
\hline Dissociation constant $\left(\mathrm{p} K_{\mathrm{a}}\right)^{\mathrm{f}}$ & $\mathrm{p} K_{1}: 9.30 ; \mathrm{p} K_{2}: 11.06$ & $\mathrm{p} K_{1}: 7.97 ; \mathrm{p} K_{2}: 9.23 ; \mathrm{p} K_{3}: 14$ & $\mathrm{p} K_{1}: 3.96 ; \mathrm{p} K_{2}: 9.61$ & $\mathrm{NA}^{\mathrm{a}}$ \\
\hline Diffusion coefficient $\left(10^{-6} \mathrm{~cm}^{2} / \mathrm{s}\right)^{b}$ & 9.934 & 9.631 & 8.853 & 1.968 \\
\hline Stokes radius (nm) & 0.292 & 0.300 & 0.323 & 0.975 \\
\hline Equivalent molar radius (nm) & 0.343 & 0.349 & 0.366 & 0.858 \\
\hline $\log K_{\mathrm{ow}}$ & $1.03^{\mathrm{c}}$ & $0.55^{\mathrm{c}}$ & $1.39^{\mathrm{c}}$ & $7.37^{\mathrm{d}}$ \\
\hline $\mathrm{SUVA}_{254}(\mathrm{~L} / \mathrm{mg} \mathrm{m})$ & 0.47 & 0.67 & 0.73 & 11.8 \\
\hline THMFP $/$ DOC $(\mu \mathrm{g} / \mathrm{mg})$ & 377 & 330 & 70 & 57 \\
\hline
\end{tabular}

\footnotetext{
a Not available.

b Calculated from the method proposed by Wilke and Chang [40].

c Obtained from [42].

d Obtained from [43].

e Seven-day formation potential measured in this research.

f Dissociation constant $\left(\mathrm{p} K_{\mathrm{a}}\right)$ [44].
}

organic-free and de-ionized water (Milli-Q SP). The DOC (dissolved organic matter) concentrations for the model compounds were prepared at $5.0 \mathrm{mg} / \mathrm{L}$. The $\mathrm{pHs}$ of the feed solutions ranged from 3 to 10 were adjusted by $0.1 \mathrm{M}$ hydrochloric acid and sodium hydroxide.

\subsection{PEG and saccharide analysis}

The MWCO of NF70 was estimated at $250 \mathrm{Da}$ in our previous research [30]. Polyethylene glycol (PEG, Aldrich) with different molecular weights $(200,300,400,600$ and $1500 \mathrm{Da})$ were used<smiles>Oc1cccc(O)c1</smiles>

1. Resorcinol<smiles>Oc1cc(O)cc(O)c1</smiles>

2. Phloroglucinol

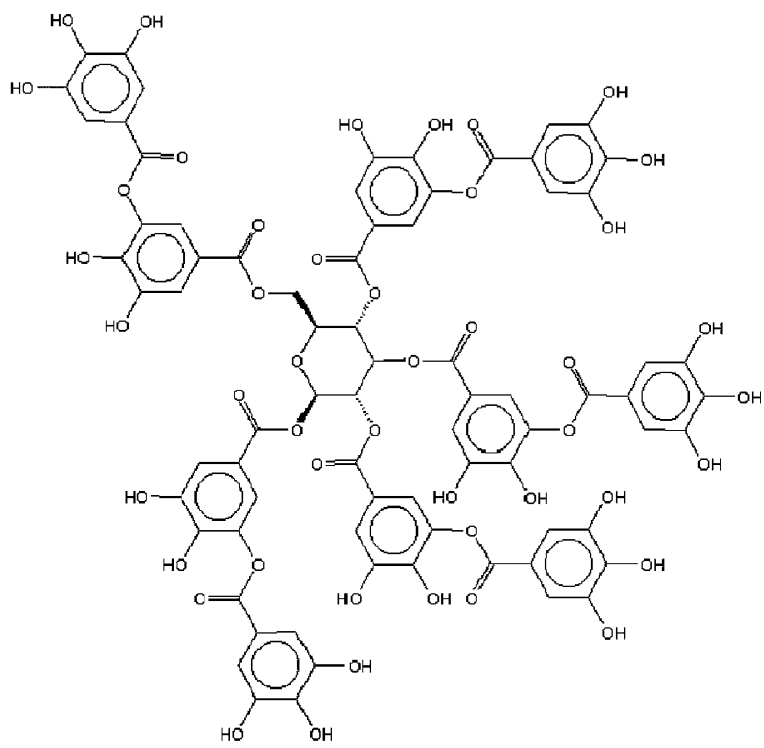<smiles>O=C(O)c1cccc(O)c1</smiles>

3. 3-hydroxybenzoic acid 4. Tannic acid

Fig. 1. Structure of the model compounds used in this study. 
to estimate the MWCO of the NF270 membrane. The DOC concentration of each PEG solution was prepared at $20 \mathrm{mg} / \mathrm{L}$. Feed and filtrate streams were analyzed for DOC concentrations to obtain the molecular weight distribution curves. The molecular weight of the $90 \%$ PEG retained on the membrane is taken as the MWCO of the NF270 membrane.

Three saccharides (glucose, sucrose and raffinose, Aldrich) were chosen as representative neutral solutes to estimate the pore radii of NF70 and NF270 membranes. The DOC concentration for each saccharide was prepared at $20 \mathrm{mg} / \mathrm{L}$.

\subsection{Filtration tests}

A laboratory cross-flow mode filtration apparatus with a flatsheet membrane cell was used for the filtration tests. Fig. 2 is a schematic diagram of the filtration module used in this study. Fresh membranes were precompacted at the standard operating pressure of $4.80 \mathrm{bar}(70 \mathrm{psi})$ with de-ionized water. Except for the saccharide retention tests, all experiments of the transmembrane pressure were maintained at 4.80 bar with the temperature at $25^{\circ} \mathrm{C}$ and cross-flow velocity at $0.30 \mathrm{~m} / \mathrm{s}$. For saccharide retention tests, the reflection coefficients were calculated using the retention data as a function of the water flux through the membrane, with operating pressures ranging from 3.4 to 11.0 bar and a temperature fixed at $25^{\circ} \mathrm{C}$. All experiments were carried out in a recycle mode with both permeate and retentate recycling back into the reservoir. Filtration of experimental solution containing model compounds was carried out for $24 \mathrm{~h}$ to avoid overestimation of rejection [31].

The retention factor, $R(\%)$ was defined as

$R(\%)=\left(1-\frac{C_{\mathrm{p}}}{C_{\mathrm{f}}}\right) \times 100$

where $C_{\mathrm{p}}$ is the concentration of permeate and $C_{\mathrm{f}}$ is the average concentration of feed and concentrate.

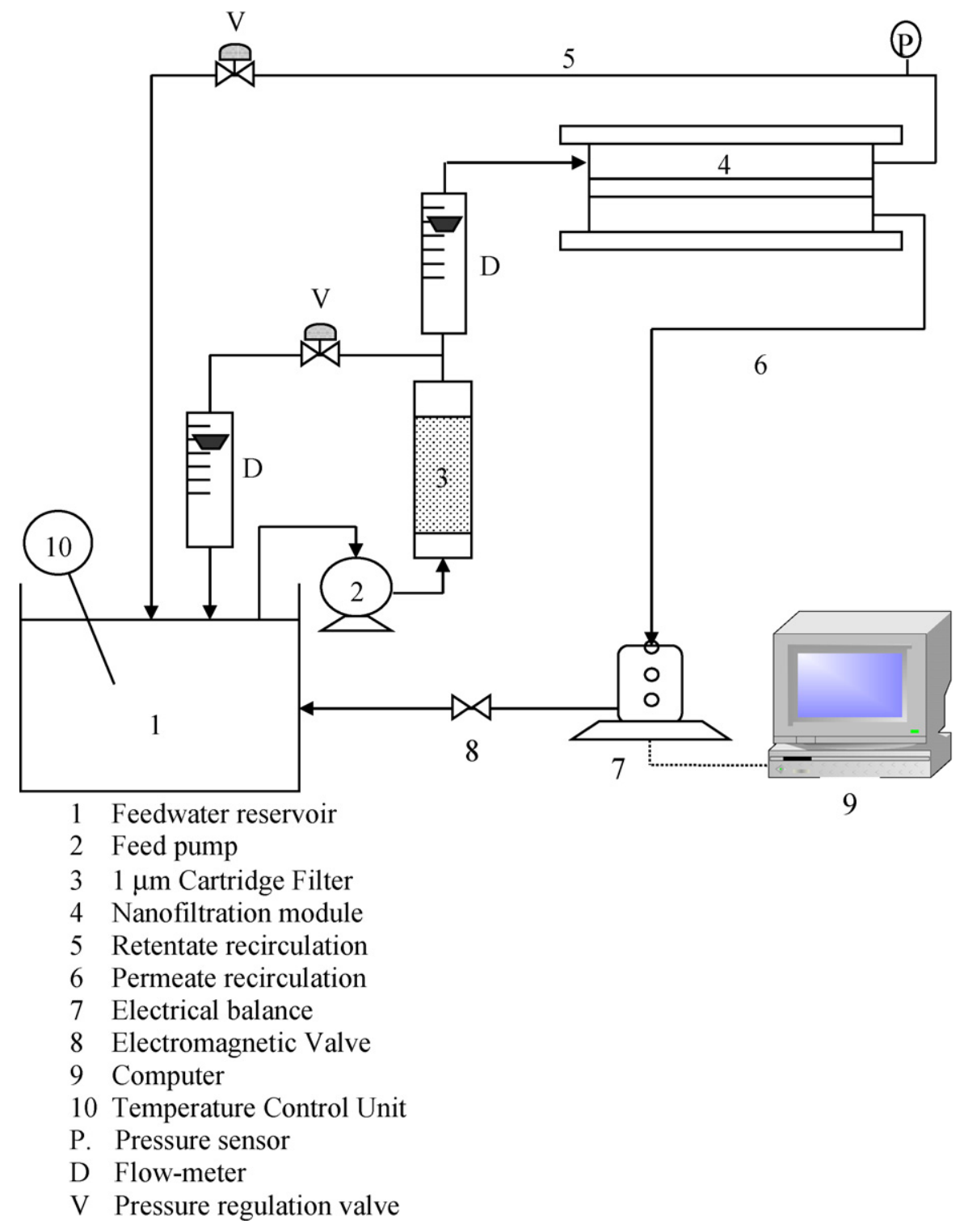

Fig. 2. Scheme of the nanofiltration module setup. 


\subsection{Streaming potential measurements}

The streaming potential $(\Delta E)$ of a clean membrane was measured to determine the zeta potential $(\zeta)$ on the membrane surface, which can be used to represent the membrane surface charge. The experimental set-up was almost identical to [32]. The dimensions of the membrane samples are $76 \mathrm{~mm} \times 26 \mathrm{~mm}$. A $0.001 \mathrm{M} \mathrm{KCl}$ solution and a pair of platina electrodes were used to measure the streaming potential, and the $\mathrm{pH}$ was adjusted by adding $4 \mathrm{M} \mathrm{NaOH}$ and $4 \mathrm{M} \mathrm{HCl}$ to the solution.

The relationship between $\Delta E$ and $\zeta$ is given by the Helmholtz-Smoluchowski equation with the Fairbrother and Mastin approach [33]:

$\xi=\frac{\Delta E \eta \kappa R_{\mathrm{el}, \mathrm{s}}}{\Delta P \varepsilon R_{\mathrm{el}}}$

where $\Delta P$ is the applied pressure, $\varepsilon$ the dielectric permittivity, $\eta$ the viscosity of the solution, $R_{\mathrm{el}}$ the electrical resistance of the electrolyte solution, and $R_{\mathrm{el}, \mathrm{s}}$ is the electrical resistance when the measurement cell was filled with solution with known specific conductivity $\kappa$.

\subsection{Analytical methods}

THMs was analyzed after the chlorination experiment. Chlorination was performed with $0.05 \mathrm{M}$ phosphate buffer $(\mathrm{pH} 7.0)$ and sodium hyperchlorite at $25^{\circ} \mathrm{C}$, with a $\mathrm{Cl}_{2}$ residual maintained at 3-5 mg/L after 7 days. The reaction was quenched after $168 \mathrm{~h}$ with sodium thiosulphate solution. DOC, $\mathrm{pH}$, and THMs were measured for water samples with model compounds, followed by the QA/QC programs set forth in Standard Methods [34]. THMs were extracted with n-pentane, and the extracts were then analyzed by GC/ECD (HP 5890-II) with a fused silica capillary column (Restek Mtx-5, $30 \mathrm{~m} \times 0.28 \mathrm{~mm}$ i.d., and $1.0 \mu \mathrm{m}$ film thickness). Water samples for DOC and UV (254 nm) analyses were filtered through a pre-washed $0.45 \mu \mathrm{m}$ filter and then

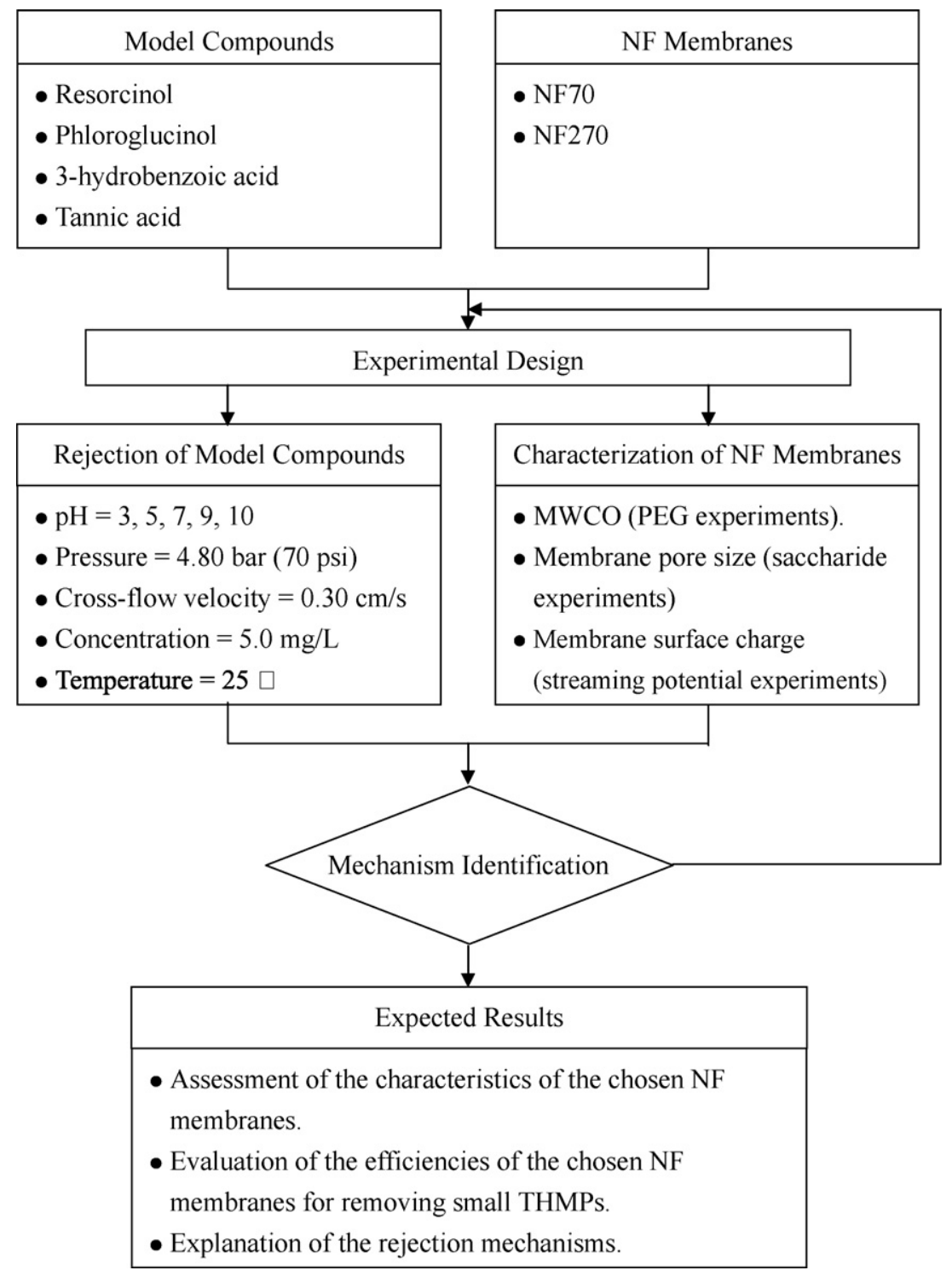

Fig. 3. Flow chart of experimental design. 
determined by a TOC instrument (O.I. Corp. model 700) and UV spectrophotometer (Hitachi U-2000).

Fig. 3 summarizes the flow chart of experimental design in this study.

\section{Results and discussion}

\subsection{Characterization of NF membranes}

The MWCO of NF70 was estimated at 250 Da in our previous research [30]. From the PEG retention curve shown in Fig. 4, the molecular weight of the PEGs retained for $90 \%$ is determined as the MWCO for the NF270 membrane. The MWCO of NF 270 was estimated at $300 \mathrm{Da}$.

According to [20], the pore size of the membrane can be evaluated using the Spiegler and Kedem membrane transport model (Eqs. (3) and (4)) [19] and the SHP model (Eq. (5)) with the retention rates of uncharged saccharides:

$R=\frac{\sigma(1-F)}{(1-\sigma F)}$

with

$F=\exp \left(-\frac{1-\sigma}{P} J_{\mathrm{v}}\right)$

where $R$ is the intrinsic rejection (\%), $\sigma$ the reflection coefficient $(\%), P$ the solute permeability $(\mathrm{m} / \mathrm{s})$, and $J_{\mathrm{v}}$ is the permeate water flux $\left(\mathrm{L} / \mathrm{m}^{2} \mathrm{~h}\right)$ :

$\sigma=1-\left(1+\frac{16 r_{\mathrm{s}}^{2}}{9 r_{\mathrm{p}}^{2}}\right)\left(1-\frac{r_{\mathrm{s}}}{r_{\mathrm{p}}}\right)^{2}\left[2-\left(1-\frac{r_{\mathrm{s}}}{r_{\mathrm{p}}}\right)^{2}\right]$

where $r_{\mathrm{s}}$ is the Stokes radius of the compound (nm), and $r_{\mathrm{p}}$ is the membrane pore radius (nm).

Table 3 is the estimated pore radii of NF70 and NF270 membranes calculated for each saccharide solute. The average pore radius of the NF70 membrane is calculated at $0.48 \mathrm{~nm}$, and the average pore radius of the NF270 membrane is calculated

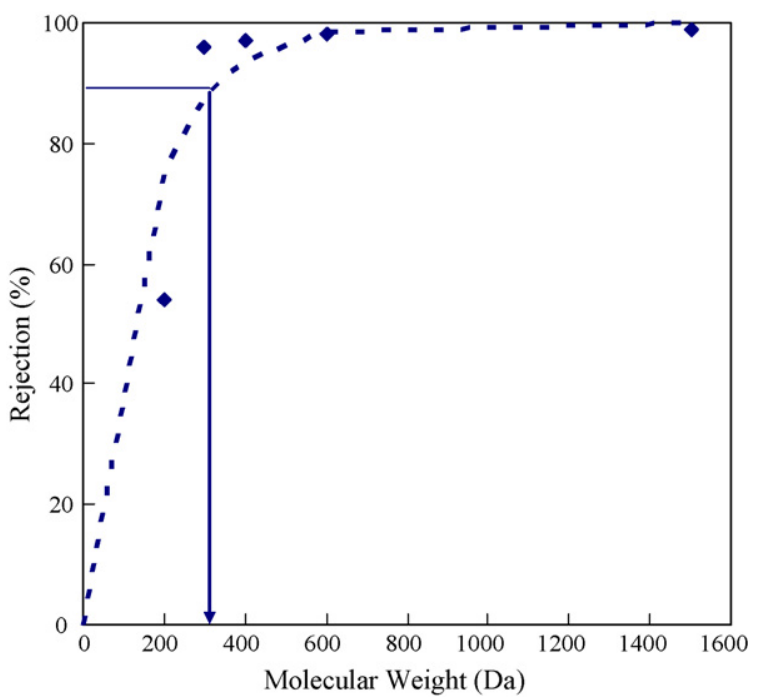

Fig. 4. PEGs retention curve by the NF270 membrane.
Table 3

Estimated pore radii of NF70 and NF270 membranes obtained from saccharide experiments

\begin{tabular}{llll}
\hline Compound & Stokes radius $(\mathrm{nm})$ & \multicolumn{2}{l}{ Estimated pore radius $(\mathrm{nm})$} \\
\cline { 3 - 4 } & & NF70 & NF270 \\
\hline Glucose & 0.365 & 0.41 & 0.43 \\
Sucrose & 0.471 & 0.44 & 0.54 \\
Raffinose & 0.584 & 0.60 & 0.65 \\
Average & - & 0.48 & 0.54 \\
\hline
\end{tabular}

at $0.54 \mathrm{~nm}$. Comparable results of estimating the average pore radii for NF70 and NF270 membranes were reported by other researchers [33-37]. These results suggest that the NF270 membrane possesses a larger pore size than the NF70 membrane, which is consistent with its lower salt rejection shown in Table 1.

Fig. 5 shows the zeta potential for the NF70 and NF270 membranes measured at different levels of $\mathrm{pH}$ value. Both membranes show negative zeta potential values at neutral $\mathrm{pH}$. The shape of the zeta potential curves indicates amphoteric surfaces; the higher $\mathrm{pH}$ values, the higher zeta potentials values. Ionizable carboxyl and amine functional groups provide the amphoteric surfaces resulting from the interfacial polymerization reaction for membrane synthesis with monomeric polyamide and polyfunctional acyl halide [33]. The isoelectric point (point-of-zero charge) of each NF membrane is near $\mathrm{pH} 4$, which means that the membrane surface is positively charged when solution $\mathrm{pH}$ less than 4 and negatively charged when solution $\mathrm{pH}$ higher than 4. Moreover, for solution $\mathrm{pH}$ higher than 4 , the higher the $\mathrm{pH}$ value was held, the more negatively charged the membrane surface was observed. The results of streaming potential measurement are consistent with the findings reported by Nghiem et al. [13] and Childress and Elimelech [33].

\subsection{Rejection properties of $N F 70$ and NF270 membranes}

Experiments were conducted with four model compounds (Table 2 and Fig. 1) in aqueous solutions at the same

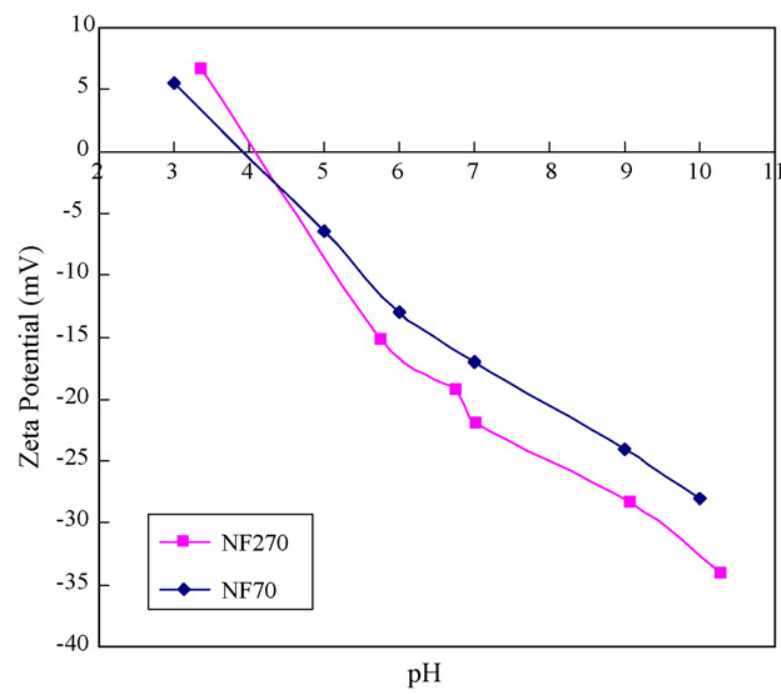

Fig. 5. Zeta potentials of NF70 and NF270 membranes as a function of $\mathrm{pH}$ 

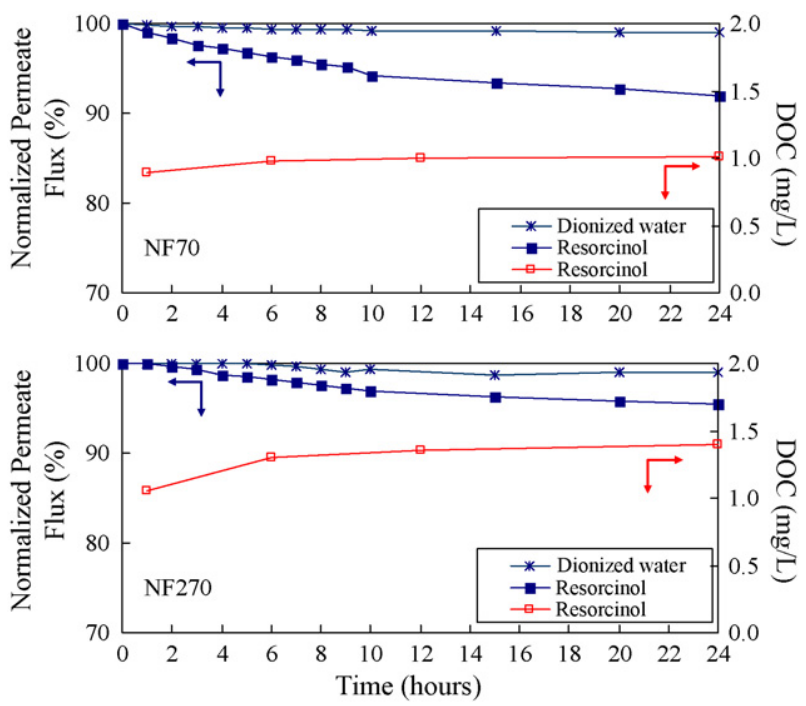

Fig. 6. Flux and permeate quality of resorcinol $(\mathrm{pH} 7$, concentration $=5.0 \mathrm{mg} / \mathrm{L})$ as a function of time for NF70 and NF270 membranes.

transmembrane pressure of 4.80 bar and cross flow velocity $(0.30 \mathrm{~m} / \mathrm{s})$. Figs. $6-9$ present the normalized permeate flux (NPF) and permeate concentration of resorcinol, phloroglucinol, 3-hydrobenzoic acid, and tannic acid as a function of time via filtration through the NF70 and NF270 membranes. The NPF is calculated by the equation as follows:

$\mathrm{NPF}(\%)=\frac{\mathrm{PF}_{\mathrm{f}}}{\mathrm{PF}_{i}} \times 100$

where $\mathrm{PF}_{\mathrm{f}}$ is the pure water flux after the membrane filtration test with the target compounds, and $\mathrm{PF}_{i}$ is the pure water flux across a new membrane $\left(\mathrm{m}^{3} / \mathrm{m}^{2} \mathrm{~h}\right)$ prior to the filtration test. The average clean water permeability of the tested membranes is $6.72 \mathrm{~L} \mathrm{~h}^{-1} \mathrm{~m}^{-2} \mathrm{bar}^{-1}$ for NF70 and $14.79 \mathrm{~L} \mathrm{~h}^{-1} \mathrm{~m}^{-2} \mathrm{bar}^{-1}$ for NF270.
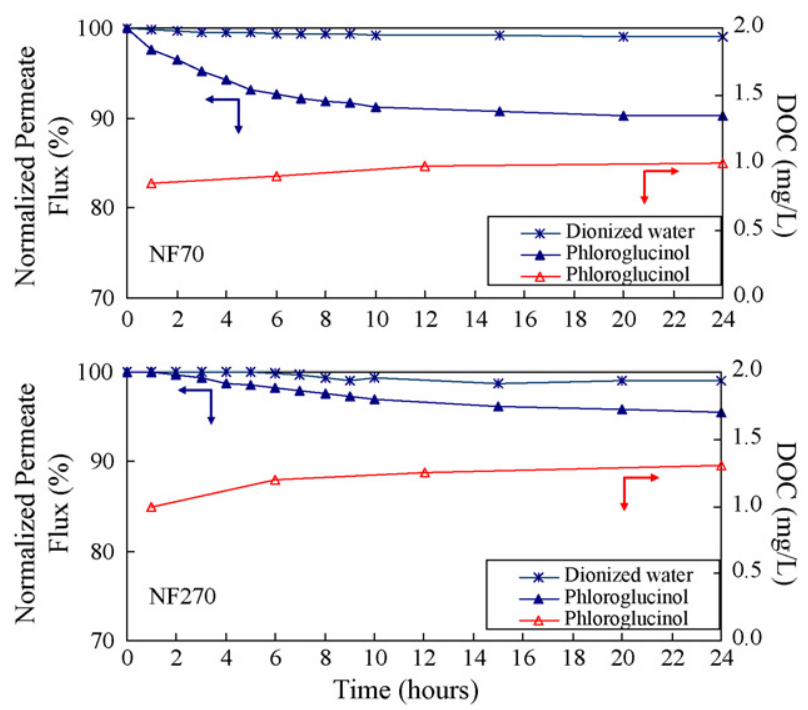

Fig. 7. Flux and permeate quality of phloroglucinol $(\mathrm{pH} \mathrm{7,} \mathrm{concentra-}$ tion $=5.0 \mathrm{mg} / \mathrm{L}$ ) as a function of time for NF70 and NF270 membranes.
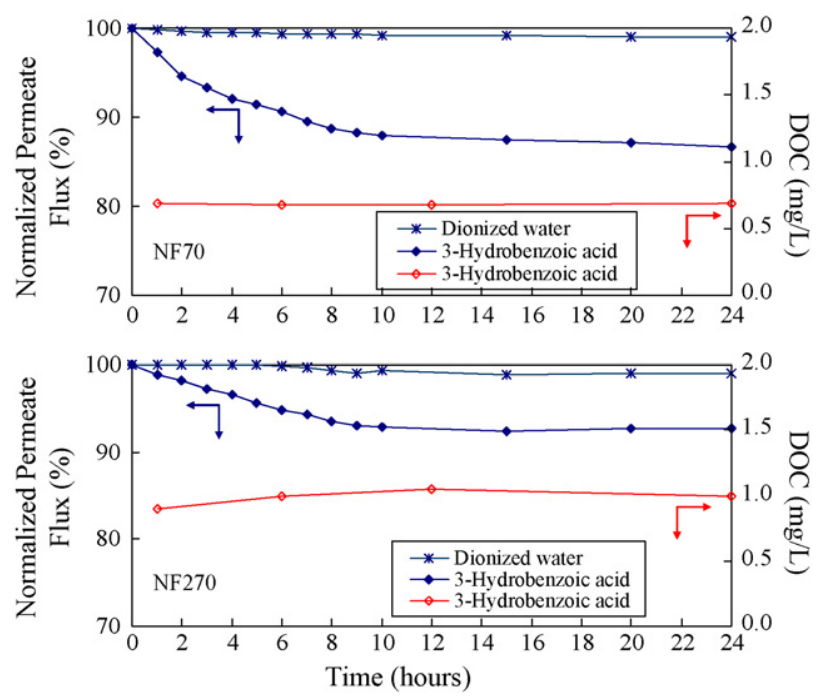

Fig. 8. Flux and permeate quality of 3-hydrobenzoic acid $(\mathrm{pH} 7$, concentration $=5.0 \mathrm{mg} / \mathrm{L}$ ) as a function of time for NF70 and NF270 membranes.

In all cases, the permeate fluxes decrease gradually in the first $10 \mathrm{~h}$ and then reach equilibrium in the presence of model compounds (Figs. 6-9). The permeate flux of NF70 membrane decline more rapidly than that of the NF270 membrane; the NF70 system reaches $90 \%$ of the initial capacity after $20,6.5$ and $1.8 \mathrm{~h}$ for phloroglucinol, 3-hydroxybenzoic acid and tannic acid, respectively. For NF270 membrane filtration tests, three small THMPs remain NPF over $90 \%$ in the filtration period, except for the tannic acid with NPF less than $90 \%$ in $5 \mathrm{~h}$.

DOC in the permeate increased slightly for resorcinol and phloroglucinol as time progressed. Rejections of 79.1 and $80.6 \%$ were observed for resorcinol and phloroglucinol, respectively, at the end of the NF70 filtration experiments. Rejections of 72.5 and $74.3 \%$ were observed for resorcinol and phloroglucinol, respectively, at the end of the NF270 filtration experiments (Figs. 6 and 7). This rejection is likely due to the adsorption of
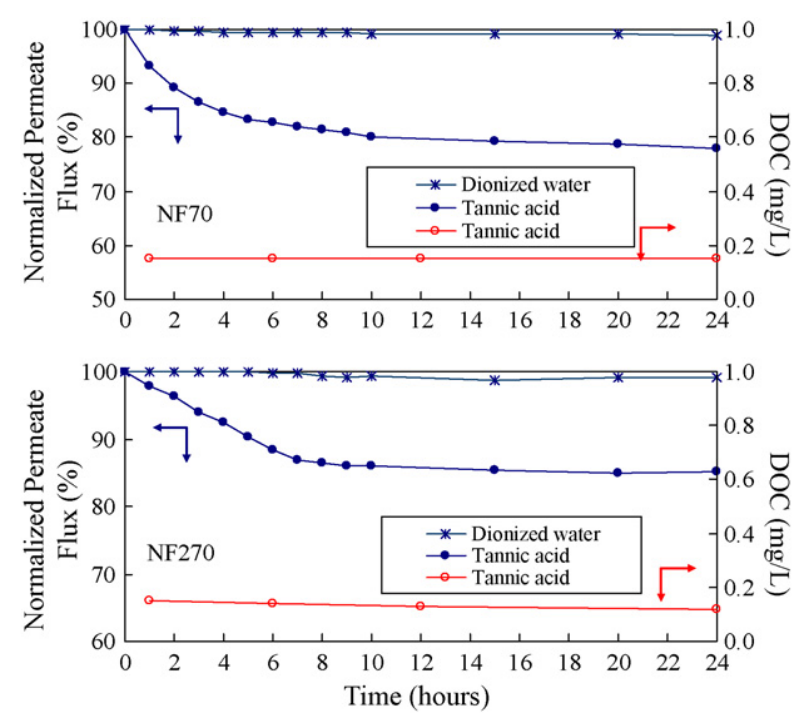

Fig. 9. Flux and permeate quality of tannic acid $(\mathrm{pH} 7$, concentration $=5.0 \mathrm{mg} / \mathrm{L})$ as a function of time for NF70 and NF270 membranes. 


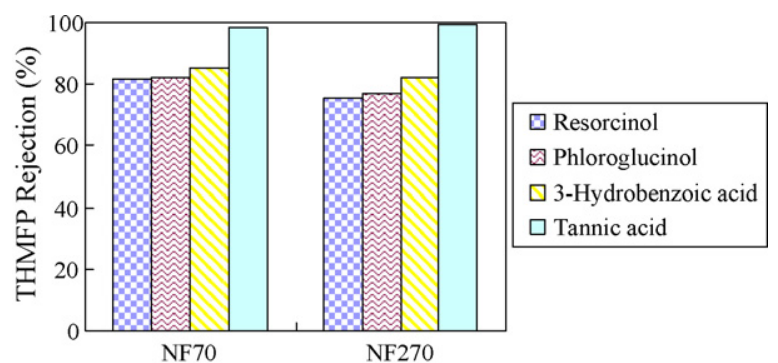

Fig. 10. Comparison of THMFP rejections for model compounds by NF70 and NF270 membranes $(\mathrm{pH} 7$, concentration $=5.0 \mathrm{mg} / \mathrm{L})$.

model compounds by hydrogen bonding between the phenolic functional groups on nonionic solutes and carbonyl functional groups on polyaimde NF membranes [13,38]. The permeate concentration presents a characteristic curve with a small breakthrough concentration, which means that the size exclusion becomes a dominant rejection mechanism when adsorption reaches equilibrium [13]. 3-Hydrobenzoic acid has a higher compound rejection (about $86.2 \%$ for $\mathrm{NF} 70$ and $80.0 \%$ for NF270 membranes) compared to phloroglucinol and resorcinol, and the DOC in permeate flux remains fairly constant during the filtration period (Fig. 8). This rejection is due to the hydrolysis of the carboxyl group on 3-hydrobenzoic acid ( $\mathrm{p} K_{1}=4.06$, Table 2) at $\mathrm{pH} 7$. Although the MW of 3-hydrobenzoic acid is very similar to that of resorcinol and phloroglucinol, this compound carries a negative charge at neutral $\mathrm{pH}$ and can be excluded by the NF70 and NF270 membranes (with negative charge at neutral $\mathrm{pH}$ ) owing to the electrostatic repulsive interaction with the membrane surfaces [39]. It can be concluded that the influence of charge exclusion is greater than the influence of compound adsorption on compound rejection at neutral $\mathrm{pH}$.

The best quality of permeate flux was observed for tannic acid with both the NF70 and NF270 membranes (Fig. 9). The removal efficiency of tannic acid is the highest among the model compounds (96.9\% for the NF70 membrane and $97.6 \%$ for the NF270 membrane) owing to its large molecular size $(0.858 \mathrm{~nm})$ compared to the pore radius of NF70 membrane $(0.48 \mathrm{~nm})$ and NF270 membrane $(0.54 \mathrm{~nm})$. There are many phenolic functional groups of tannic acid (Fig. 2), which may increase the possibility of adsorption onto polyamide membrane surfaces as mentioned above and thus resulting in more flux decline compared with the other three small THMPs (Figs. 6-9).

Fig. 10 shows the THMFP rejections of model compounds by NF70 and NF270 membranes. The trend is the same as the DOC rejection, i.e., the rejections of the three small THMPs in permeate for the NF70 membrane are higher than that for the NF270 membrane, and the rejection of tannic acid is the highest for both NF70 and NF270 membranes. The high permeability of the NF270 membrane is likely due to its larger pore size. For the three small THMPs which are partially rejected by the NF270 membrane, the solute flux increases with the pure water flux and results in slightly lower rejection compared with the NF70 membrane (Figs. 6-9). However, for the highly rejected tannic acid, the high permeability in NF270 filtration comes from the pure water flux so that the rejection of tannic acid is slightly higher by the NF270 than by the NF70 membrane.
From the above experiments, it can be concluded that the NF70 and NF270 membranes are effective in removing DOC and THMFP for molecules with a wide range of molecular mass. For small compounds with high THM yield, other treatment processes may be utilized together with nanofiltraiton to enhance the removal of small compounds.

\subsection{Effect of pH on compound rejections}

The diffusivity coefficient and Stokes radius of each model compound in Table 2 were determined by the Wilke and Chang and the Stokes-Einstein equations [40]. The Stokes radii of three small THMPs are smaller than the average pore radii of the NF70 and NF270 membranes, and the Stokes radius of tannic acid is significantly larger than the average pore size of both membranes. Thus, it is expected that the retention of the small THMPs would be very low and the retention would be complete for tannic acid if the rejection mechanism was only based on the steric hindrance. From the experimental data in Figs. 6-10, it indicates that the rejections of three small THMPs are high (72.5-86.2\%), which implies that there might be another controlled mechanism, such as the charge effect, affecting the rejection ratio.

To evaluate the effect of charge exclusion, feed solutions of model compounds with different $\mathrm{pH}$ values were applied on both NF membranes. Fig. 11 shows the relationship between the solution $\mathrm{pH}$ values and model compounds rejections. All data shows that rejection of all model compounds increases with an
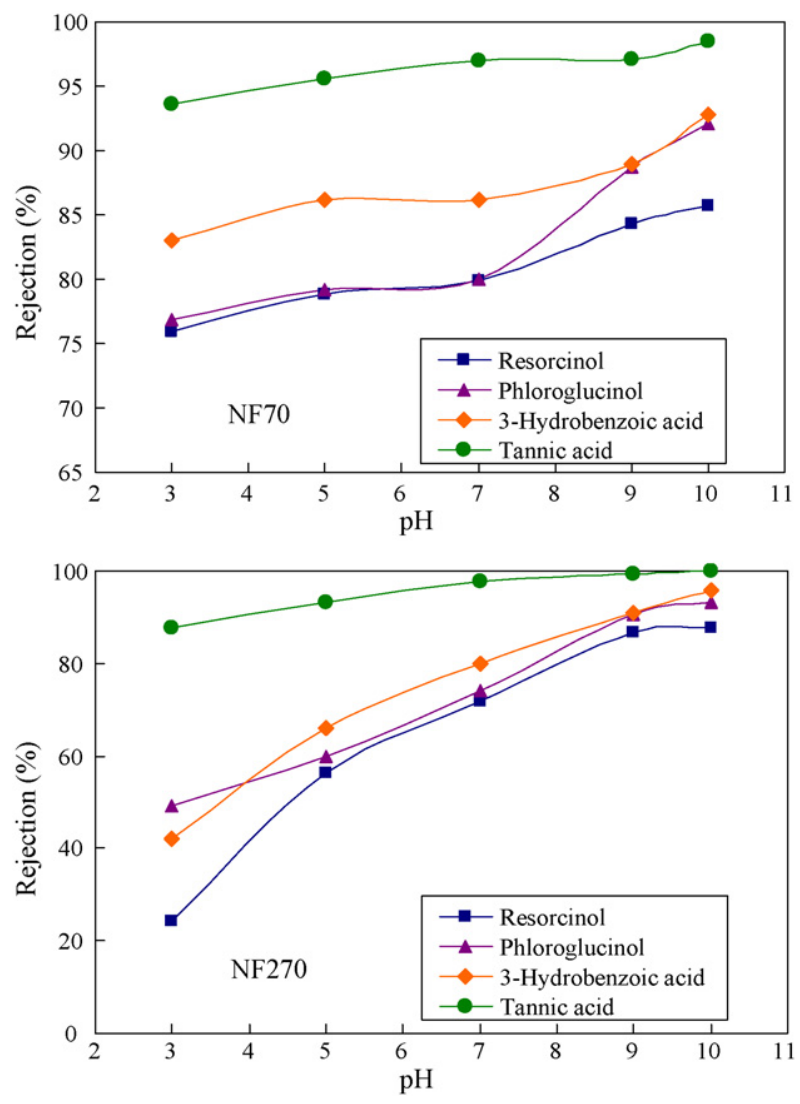

Fig. 11. Effect of $\mathrm{pH}$ on rejection of model compounds by NF70 and NF270 membranes (initial concentration $=5 \mathrm{mg} / \mathrm{L}$ ). 
increase in $\mathrm{pH}$ for both $\mathrm{NF}$ membrane. A more profound $\mathrm{pH}$ effect was observed for the NF270 membrane. This $\mathrm{pH}$ effect is due to the polyelectrolyte character of the model compounds and the negatively charged NF membrane characteristics, which is discussed below.

For the three small THMPs, at $\mathrm{pH}$ values lower than the ionization constant of each compound, the rejection mechanism is based on the sieve effect and the adsorption of model compounds on NF membranes, as mentioned above. Therefore, the rejections of the three small THMPs at low $\mathrm{pH}$ values are significantly less than at high $\mathrm{pH}$ values, especially for the NF270 membrane. 3-Hydrobenzoic acid has a slightly higher compound rejection compared to phloroglucinol and resorcinol, which may be attributed to its low $\mathrm{p} K_{1}$ value. The low $\mathrm{p} K_{1}$ value cause the carboxyl functional groups to start hydrolysis at $\mathrm{pH} 4.06$, leading to an increase in electrostatic repulsive interaction with the NF70 and the NF270 membranes [39]. However, at pH 10, two phenolic functional groups of phloroglucinol and one carboxyl plus one phenolic functional group of 3-hydrobenzoic acid are dissociated. At high $\mathrm{pH}$, the charge density and molecular size of phloglucinol are similar to those of 3-hydrobenzoic acid. Therefore, the rejection efficiencies of the two compounds are similar in both NF membranes.

For tannic acid with medium MW at $\mathrm{pH}$ values lower than its ionization constant, the molecule is neutral and may form a compact coiled conformation because of the suppression of dissociation of ionogenic groups, the same as humic acid and fulvic acid studied by [41], which leads to a restriction of electrostatic intra-chain repulsion and causes a reduction in the tannic acid molecular size. Therefore, the rejection mechanism is mainly due to the "sieve effect" under acidic conditions. However, at $\mathrm{pH}$ values higher than the ionization constant of tannic acid, the molecule unfolds because of the ionization of ionogenic groups leading to electrostatic repulsion between macromolecule segments. At the higher $\mathrm{pH}$ value, the tannic acid molecule is negatively charged with a larger molecular size which can be rejected more effectively by both the "sieve effect" and the "charge effect" on the NF membranes. As a result, the removal efficiency of tannic acid increases from $93.6 \%$ up to $98.5 \%$ filtered by the NF70 membrane and from 87.6 to $99.9 \%$ filtered by the NF270 membrane.

There is a notable trend in the experimental data of NF270 membrane that the rejections of all model compounds show strong correlation with the $\mathrm{pH}$ values (Fig. 11), which implies that the electrostatic interaction between the NF270 membrane surface and the model compounds grows stronger as the solution $\mathrm{pH}$ rises. The electrostatic interaction between membrane surface and model compounds is confirmed by the results of the zeta potential measurements at different $\mathrm{pH}$ values (Fig. 5).

Since the membranes are more negatively charged as $\mathrm{pH}$ values higher above the isoelecric point, the electrostatic repulsion force between the membrane surface and the model compounds increases as $\mathrm{pH}$ rises. Dissociation of the functional groups on the membrane and the model compounds intensifies the electrostatic interaction between the NF70 and/or NF270 membranes and model compounds. As a result, the model compounds rejections should increase as $\mathrm{pH}$ rises. The trend of the experimental data shown in Fig. 11 indicates that the NF70 membrane is less pH sensitive than the NF270 membrane (Fig. 5). This implies that the solution $\mathrm{pH}$ would greatly affect the performance of NF270 membrane; therefore, the application of NF270 at different $\mathrm{pH}$ values should be evaluated and adjusted to achieve the optimum filtration performance. On the other hand, as shown in Figs. 6-9, the NF270 membrane (with average clean water permeability of $14.79 \mathrm{~L} \mathrm{~h}^{-1} \mathrm{~m}^{-2}$ bar $^{-1}$ ) exhibits the superior permeation rate than the NF70 membrane (with average clean water permeability of $6.72 \mathrm{~L} \mathrm{~h}^{-1} \mathrm{~m}^{-2}$ bar $^{-1}$ ). It suggests that the two-fold increase in the NF270 membrane productivity as compared with the NF70 membrane would dramatically reduce energy consumption at the same operating conditions.

\section{Conclusions}

The rejections of three small THMPs (resorcinol, phloroglucinol and 3-hydrobenzoic acid) as well as tannic acid with a wide range of molecular mass by the NF70 and NF270 membranes are effective. Filtered solutes with MWs less than the MWCO of membranes or with Stokes radii less than the membrane pore radius can be rejected satisfactorily. The compound rejection of 3-hrdrobenzoic acid is the highest due to the electrostatic repulsive interaction with the nanofiltration membranes and its ionized functional groups.

Model compounds rejection increases with $\mathrm{pH}$ in the solution due to the dissociation of ionizable functional groups on the model compounds and the electric interaction between the compounds and membranes. High removals of THMPs were observed at high $\mathrm{pH}$ values. The charge exclusion is found to be the prevailing mechanism of small model compounds retention by the negatively charged nanofiltration membranes. The size exclusion mechanism also is observed to be important but not sufficient for the unionized small organic molecules rejections.

The NF270 membrane is more pH sensitive than the NF70 membrane. This sensitivity implies that the solution $\mathrm{pH}$ would greatly affect the performance of the NF270 membrane. Further research should be focused on the application of NF270 at different $\mathrm{pH}$ values, and the optimum filtration performance should be determined.

In general, the NF270 membrane exhibits the superior permeation rate, which takes an advantage over the NF70 membrane from the aspect of energy conservation.

\section{References}

[1] C.I. Chaidou, V.I. Georgakilas, C. Stalikas, M. Saraci, E.S. Lahaniatis, Formation of chloroform by aqueous chlorination of organic compounds, Chemosphere 39 (1999) 587-594.

[2] Health Canada, Guidelines for Canadian drinking water quality: guideline technical document: trihalomethanes, in: Federal-Provincial-Territorial Committee on health and the Environment, Ottawa, Ontario, 2006.

[3] US EPA, 2004 Edition of the Drinking Water Standards and health Advisories, EPA 822-R-04-005, Office of Water, U.S. Environmental Protection Agency, Washington, DC, 2004.

[4] WHO, Guidelines for Drinking-Water Quality, 3rd ed., 2003.

[5] National Health and Medical Research Council, "Australian Drinking Water Guidelines", Agricultural and Resource Management Council of Australia and New Zealand, Commonwealth of Australia, 1996. 
[6] Environmental Health Directorate, Summary of Guidelines for Canadian Drinking Water Quality. Prepared by the Federal-Provincial Subcommittee on Drinking Water of the Federal-Provincial Committee of Environmental and Occupational Health, April 2003.

[7] Ministry of Health, NZ, Drinking-Water Standards for New Zealand, 2000.

[8] USEPA, National primary drinking water regulations: stage 2 disinfectants and disinfection byproducts rule (stage 2 DBPR), final rule, Federal Reg. 71 (2006) 387-493.

[9] US EPA, $N$-nitrosodimethylamine CASRN 62-75-9, Integrated Risk Information Service (IRIS) Substance File, 1997.

[10] J.A. Nilson, F.A. Digiano, Influence of NOM composition on nanofiltration, J. Am. Water Works Assoc. 88 (1996) 53-66.

[11] D.M. Owen, G.L. Amy, Z.K. Chowdhury, R. Paode, G. McCoy, K. Viscosil, NOM characterization and treatability, J. Am. Water Works Assoc. 87 (1995) 46-63.

[12] T. Wintgens, M. Gallenkemper, T. Melin, Endocrine disrupter removal from wastewater using membrane bioreactor and nanofiltration technology, Desalination 146 (2002) 387-391.

[13] L.D. Nghiem, A.I. Schafer, M. Elimelech, Removal of natural hormones by nanofiltration membranes: measurement, modeling, and mechanics, Environ. Sci. Technol. 38 (2004) 1888-1896.

[14] T.U. Kim, G. Amy, J.E. Drewes, Rejection of trace organic compounds by high-pressure membranes, Water Sci. Technol. 51 (2005) 335-344.

[15] M.R. Wiesner, J. Hackney, S. Sethi, J.G. Jacangelo, J.M. Laine, Cost estimates for membrane filtration and conventional treatment, J. Am. Water Works Assoc. 86 (1994) 33-41.

[16] J.G. Jacangelo, J. Demarco, D.M. Owen, S.J. Randtke, Selected processes for removing NOM—an overview, J. Am. Water Works Assoc. 87 (1995) 64-77.

[17] B. van der Bruggen, J. Schaep, W. Maes, D. Wilms, C. Vandecasteele, Nanofiltration as a treatment method for the removal of pesticides from ground water, Desalination 117 (1998) 139-147.

[18] Y. Kiso, Y. Nishimura, T. Kitao, K. Nishimura, Rejection of nonphenylic pesticides with nanofiltration membranes, J. Membr. Sci. 171 (2000) 229-237.

[19] K.S. Spiegler, O. Kedem, Thermodynamics of hyperfiltration (reverse osmosis): criteria for efficient membranes, Desalination 1 (1966) 311-326.

[20] X.L. Wang, T. Tsuru, S. Nakao, S. Kimura, Electrolyte transport through nanofiltraiton membranes by the space-charge model and the comparison with Teorell-Mayer-Sievers model, J. Membr. Sci. 103 (1995) 117-133.

[21] W.R. Bowen, H. Mukhtar, Characterization and prediction of separation performance of nanofiltration membranes, J. Membr. Sci. 112 (1996) 263-274.

[22] E.E. Chang, P.C. Chaing, Y.W. Ko, W.S. Lan, Characteristics of organic precursors and their relationship with disinfection by-products, Chemosphere 44 (2001) 1231-1236.

[23] P.C. Chiang, E.E. Chang, C.H. Liang, NOM characteristics and treatabilities of ozonation processes, Chemosphere 46 (2002) 929-936.

[24] C.W.K. Chow, R. Fabris, M. Drikas, A rapid fractionation technique to characterize natural organic matter for the optimization of water treatment processes, J. Water Supply Res. Technol.-Aqua 53 (2004) 85-92.
[25] G.L. Amy, B.C. Alleman, C.B. Cluff, Removal of dissolved organic-matter by nanofiltration, J. Environ. Eng.-ASCE 116 (1990) 200-205.

[26] D.A. Reckhow, P.C. Singer, R.L. Malcolm, Chlorination of humic materials-by-product formation and chemical interpretations, Environ. Sci. Technol. 24 (1990) 1655-1664.

[27] D.L. Norwood, J.D. Johnson, R.F. Christman, J.R. Hass, M.J. Bobenrieth, Reactions of chlorine with selected aromatic models of aquatic humic material, Environ. Sci. Technol. 14 (1980) 187-190.

[28] G.V. Korshin, C.W. Li, M.M. Benjamin, Monitoring the properties of natural organic matter through UV spectroscopy: a consistent theory, Water Res. 31 (1997) 1787-1795.

[29] IRCHS, http://www.ecn.purdue.edu/CMTI/IRCHS/.

[30] Y.L. Lin, P.C. Chiang, E.E. Chang, Reduction of disinfection by-products precursors by nanofiltration process, J. Hazard. Mater. 137 (2006) 324-331.

[31] K. Kimura, S. Toshima, G. Amy, Y. Watanabe, Rejection of neutral endocrine disrupting compounds (EDCs) and pharmaceutical active compounds (PhACs) by RO membranes, J. Membr. Sci. 245 (2004) 71-78.

[32] J.M.M. Peeters, M.H.V. Mulder, H. Strathmann, Streaming potential measurements as a characterization method for nanofiltration membranes, Colloids Surf. A: Physicochem. Eng. Aspects 150 (1999) 247-259.

[33] A.E. Childress, M. Elimelech, Effect of solution chemistry on the surface charge of polymeric reverse osmosis and nanofiltration membranes, J. Membr. Sci. 119 (1996) 253-268.

[34] APHA Standard Methods for the Examination of Water and Wastewater, 20th ed., American Public Health Association, Washington, DC, 1998.

[35] B. van der Bruggen, J. Schaep, D. Wilms, C. Vandecasteele, Influence of molecular size, polarity and charge on the retention of organic molecules by nanofiltration, J. Membr. Sci. 156 (1999) 29-41.

[36] B. van der Bruggen, B. Daems, D. Wilms, C. Vandecasteele, Mechanisms of retention and flux decline for the nanofiltration of dye baths from the textile industry, Sep. Purif. Technol. 22-23 (2001) 519-528.

[37] N. Hilal, H. Al-Zoubi, N.A. Darwish, A.W. Mohammad, Characterization of nanofiltraiton membranes using aromatic force microscopy, Desalination 177 (2005) 187-199.

[38] M.E. Williams, J.A. Hestekin, C.N. Smothers, D. Bhattacharyya, Separation of organic pollutants by reverse osmosis and nanofiltration membranes: mathematical models and experimental verification, Ind. Eng. Chem. Res. 38 (1999) 3683-3695.

[39] Y.Z. Xu, R.E. Lebrun, Investigation of the solute separation by charged nanofiltration membrane: effect of $\mathrm{pH}$, ionic strength and solute type, J. Membr. Sci. 158 (1999) 93-104.

[40] C.J. Geankoplis, Transport Processes and Unit Operations, 3rd ed., Prentice-Hall, Englewood Cliff, NJ, 1993.

[41] M. Kabsch-Korbutowicz, K. Majewska-Nowak, T. Winnicki, Analysis of membrane fouling in the treatment of water solutions containing humic acids and mineral salts, Desalination 126 (1999) 179-185.

[42] Syracuse Research Corporation Interactive PhysProp Database Demo, 2004.

[43] Virtual Computational Chemistry Laboratory, ALOGPS 2.1 Program, 2006.

[44] Serjeant, Dempsey, Ionisation Constants of Organic Acids in Aqueous Solution, IUPAC Chemical Data Series, No. 23, Pergamon Press, 1979. 